\title{
Influence Research of Urban Poverty in Transition Period Market Process
}

\author{
Yanyang Yan , Pengfei Liu \\ College of Finance and statisticsin Hunan University, Changsha, Hunan 410079
}

\begin{abstract}
Poverty is the key issue to be discovered in economy, sociology, anthropology and etc. In china, with the increasing developments in economy and the process of marketing, the poverty in urban has become more and more obviously. However, there are rare references concerns about the relationships between them. In this paper, the unemployment rate of urban population index indicates the extent of urban povertyandthe market index constructed by Fan Gang, who represents the degree of market process. The panel data was collected in $\mathbf{3 0}$ different provinces in China from the year of 1997 to 2009. After researching the market process which affect the poverty in urban, there is an inverted " $U$ " relationship between the poverty in urban and process of marketing in china. At last, some policies suggestion was raised to solve relevant problems in the issue of poverty in urban.
\end{abstract}

Keywords- Urban Poverty; Marketing Process; Inverted "U" Relationship

\section{INTRODUCTION}

With the rapid development of China's economy and society, urban poverty highlights and market accelerated gradually become two extreme problems that people are concerned. On the one hand, since the end of last century, further social reforms were promoted, so the old pattern of city interests was broken and new urban social relations were reconstructed, which produced unprecedented impact on urban development and social space, and the rapid expansion of the urban poor will become an inevitable result. According to statistics, by 2013 August, there were 2.09 million minimum targets in total, accounting for $4.4 \%$ of the national total nonfarm population. Urban poverty has become a social problem that cannot be ignored. On the other hand, for 33 years of reform and opening, China's market progress has been made universally acknowledged success. During the market reform, China's economy has maintained fast growth of $10 \%$ per year. Most people's living standards improved significantly, and China's economic strength has markedly increased. The rapid development of the market process has become all levels of government of our country and people's pursuit and hot issues of concern.

In view of the above two hot issues, from many angles and in-depth level, academia consider the reasons for their development. However, few scholars connect these two questions. As everyone knows, the process of marketization development will promote the economic development, the political and economic system reform, and the optimal allocation of resources and a series of social problems. Then what role doesmarket development play in city urbanization? And what is the relationship with city poverty problem? Will it promote the deepening contradictions of urban poverty or relieve the pressure?

\section{STUDY DESIGN}

\section{A. Model Set}

By building the following regression equation as Formula 1, we study the impact of market process on urban poverty:

$$
U P_{i t}=\alpha+\beta_{1} P O M_{i t}+\beta_{2} P O M_{i t}^{2}+\sum_{j=1}^{k} \gamma_{j} X_{j i t}+\varepsilon_{i t}
$$

Among above, $U P_{i t}$ refers to the extent of urban poverty of number i province in year t; $P O M_{i t}$ refers to the degree of market of number i province in year $\mathrm{t} ;{ }^{X_{i t}}$ refers to other variables influencing urban poverty; ${ }^{\varepsilon_{i t}}$ refers to random disturbance.

\section{B. Index Selection}

1) Explained variables: the extent of urban poverty

Few existing studies quantify the extent of urban poverty indicators. Taking into account that we analyze urban poverty from the perspective of the urban poor population, in order to carry out empirical research, we mainly take urban unemployment as proxy for the extent of urban poverty, and in accordance with the relevant economic theory and practical experience, from several aspects of the tertiary industry employment, urban consumer price index, level of education and per capita GDP in different region, to control related variables that may have a significant impact on urban poverty.

2) Explanatory variables: the degree of Marketization

In order to consider the comprehensive influence of market process on city poverty, we take China marketization index as proxy variable of degree of marketization. Make horizontal comparison across the market-oriented, and at the same time reflect the changes in market-oriented provinces along the chronological order.

\section{3) Controlled variables}

a)The proportion of tertiary industry employment: since in town, tertiary industry can provide relatively more employment opportunities for laid-off or career crowd, so that help to reduce the number of urban poor and reduce the extent of urban poverty.

b) Urban consumer price index: under normal circumstances, the higher the urban consumer price level is, 
the higher the level of inflation cityis, and the more severeresidents' polarization level will be. Therefore, the extent of urban poverty will increase.

c) Level of education:Cultural and technical quality of workers determines the ability and opportunity to its competitive jobs.Imbalance between labor supply and demand structures and low quality of workers will be difficult to meet the needs of development of productive forces, industrial restructuring and technical Update accelerate, leading to unemployment increasing. The higher the education level of a region, the little unemployed population will be. In this paper, we take the proportion of diploma population accounting for total population.

d) GDP per capita: GDP per capita in different regions reflects the general economic situation of a region of income. Areas with high per capita GDP generally have high level of economic development and sound social security system, and urban poverty will be alleviated.

\section{Data Description}

China's market index data compiled from Fan GangChina market index - Regional market relative process 2011 Report; the remaining data is calculated from the raw data according to China Statistical Yearbook. It should be noted that, for the very small number of missing data, we calculate it by linear interpolation of the index based on the data.

\section{EMPIRICAL ANALYSIS}

In this part we study the impact of marketization process on urban poverty levels, and explore the interaction mechanism. Market index and urban poverty scatterplot is as Figure 1, among which, the abscissa represents the market index, while the ordinate represents the unemployment rate of urban population. It can be seen visually thatthe process of marketization and the city poverty form an inverted "U" relationship. With the deepening of the process of marketization, urban poverty shows the trend of first increase and then decrease.

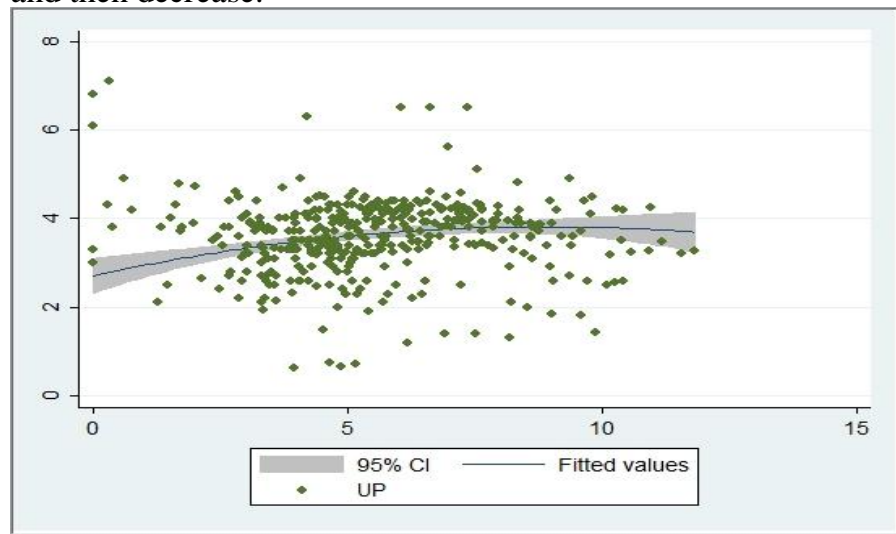

Figure 1. Impact of Marketization Process on Urban Poverty

Descriptive statistics of each index variable is shown as Table 1. We can see thatmean value of poverty in our country is 3.5894 , which is a moderate degree of city poverty, but the gap between the maximum and minimum values is large. The difference of degree of regional markets is quite large. In addition, urban consumer price index of controlled variables is relatively concentrated, however, the proportion of tertiary industry employment, education level and GDP per capita in different regions exist some gap to a certain extent.

Table 1. Descriptive Statistics of Each Index Variable

\begin{tabular}{ccccc}
\hline Variable name & Mean & Standard deviation & $\begin{array}{c}\text { Maximu } \\
\mathrm{m}\end{array}$ & $\begin{array}{c}\text { Minimu } \\
\mathrm{m}\end{array}$ \\
Urban poverty & 3.5894 & 0.844 & 7.1 & 0.62 \\
Marketization level & 5.508 & 2.189 & 11 & 0 \\
The third industry & 0.143 & 0.048 & 0.271 & 0.0035 \\
employment population & & & & \\
proportion & & 2.388 & 108.9 & 96.4 \\
Urban consumer price index & 101.49 & $4.37 \mathrm{e}-004$ & $4.01 \mathrm{e}-$ & $7.8 \mathrm{e}-$ \\
Education level & $5.6 \mathrm{e}-$ & & 003 & 005 \\
& 004 & 12242 & 69164 & 411.16 \\
GDP per capita & 14093 & & & \\
\hline
\end{tabular}


Table 2. Impact of Marketization Process on Urban Poverty

\begin{tabular}{|c|c|c|}
\hline Variable coefficient & Model 1 & Model 2 \\
\hline Constant term ( $\alpha$ ) & $\begin{array}{c}2.7089 * * * \\
(13.537)\end{array}$ & $\begin{array}{c}2.008 * * * \\
(8.6126)\end{array}$ \\
\hline $\operatorname{POM}\left(\beta_{1}\right)$ & $\begin{array}{c}0.2492 * * * \\
(3.5362)\end{array}$ & $\begin{array}{c}0.2171 * * * \\
(3.2763)\end{array}$ \\
\hline$\left.P^{2}{ }_{(} \beta_{2}\right)$ & $\begin{array}{l}-0.014 * * \\
(2.3725)\end{array}$ & $\begin{array}{l}-0.009 * * \\
(2.1582)\end{array}$ \\
\hline $\operatorname{TEPP}\left(\gamma_{1}\right)$ & & $\begin{array}{c}-4.8895 * * * \\
(5.6651)\end{array}$ \\
\hline $\operatorname{RCPI}\left(\gamma_{2}\right)$ & & $\begin{array}{c}0.3455^{* *} \\
(2.1875)\end{array}$ \\
\hline $\mathrm{EP}\left(\gamma_{3}\right)$ & & $\begin{array}{l}-0.0132 \\
(0.8109)\end{array}$ \\
\hline $\operatorname{CGDP}\left({ }^{\gamma_{4}}\right)$ & & $\begin{array}{c}-0.0004 * \\
(1.9833)\end{array}$ \\
\hline Adjustment $R^{2}$ & 0.0652 & 0.0712 \\
\hline F Value & 13.9538 & 18.29 \\
\hline D.W & 1.8705 & 2.3254 \\
\hline
\end{tabular}

To effectively study the impact of the marketization process on urban poverty, taking into account the panel data may appear sectional heteroscedasticity problem,we use White heteroskedasticity consistent standard to calculate the coefficient covariance matrix difference,so thatOLS estimation results are more reliable.

The regression results in Table 2 well support our previous hypothesis. We can see that in model 1 market index variable coefficient is positive, while its squared term coefficient is negative, and at 5\% confidence levels is significant, which shows the inverted " $U$ " relationship between the marketization process and urban poverty. There may exist omitted variable problem in the above analysis, to this end, we joined the controlled variables of the proportion of the population of tertiary industry, the consumer price index, level of education and per capita GDP, to further investigate the influence of marketization process on urban poverty. We can see that after the addition of the control variables, the inverted "U" relationship between the marketization process and urban poverty is still very significant. In addition, proportion of the population in the tertiary industry variable coefficient in controlled variable is

-4.8895 , and is significantly negative, which reveals that the tertiary industry populationcan effectively alleviate the urban poverty problems; urban consumer price index coefficient is positive, and at the 5\% level is significant, which reveals that Inflation accelerate the pace of urban poverty. Per capita GDP is also significantly affected the urban poor under the appropriate level, and only educational level indicator is not significant, although it is consistent with the expected.

\section{CONCLUSIONS AND POLICY RECOMMENDATIONS}

From the perspective of the analysis of the urban poor, we have analyzed the causes of urban poverty, and combined with the impact ofmarketization process on these factors, to study the relationship between marketization and urban poverty. Studies have shown that, there is an inverted "U"non-linear relationship between the marketization process and urban poverty. That is to say, the rapid development of marketization firstly exacerbates urban poverty, but with appropriate measures to improve, marketization process can effectively reduce the extent of urban poverty. At the same time of promoting the rapid development of economy and society, it can also provide 
constructive support to safeguard social stability.This paper concludes with a more important policy implications. Accelerating the process of China's marketization should not only consider the economic growth effect it brings, but also consider the social impact it produces. In view of this, we put forward several aspects of the proposal as follow:

First, complete set of institutional measures. As one of the social mutual construction, government plays an irreplaceable role in the market process of governance in urban poverty and accelerates. Government should build a positive security policy, and gradually establish a series of basic security system to solve the basic living of the urban poor.

Second, improve the urban poor personal qualities and skills, and cultivate their enthusiasm of participating in marketization. Marketizationdevelopment offers many opportunities for people to improve their living conditions and poverty please, to improve the ability of each individual, especially the urban poor, to participate in the market economy and the use economic development opportunities, so that reduce social poverty groups competing for market fragility.

Third, improve the market system, to enhance the role of nonprofit organizations in combating poverty. Market reform is economic growth pusher, but fast system inevitably will produce a series of social problems. Nonprofit organizations play an important role in alleviating urban poverty, so we should gradually improve the operation of non-profit organizations involved in poverty alleviation mechanism, so as to make up the market and the government to play a greater efficacy when failure.

\section{REFERENCE}

[1] Giles. J, Albert Park and Fang Cai, "How Has Economic Restructuring Affected China's Urban Workers?" [J], China Quartely, 2006(185)

[2] Meng . X, Robert Gregory and Youjuan Wang, "Poverty, Inequality and Growth in Urban China 1986--2000"[J],Journal of Comparative Economics ,2005(33)

[3] Appleton, Simon and Lina Song, "The Myth of the New Urban Poverty? Trends in Urban Poverty in China 1998--2002'[p],working paper at University of Oxford .

[4] Hsieh. C and P.J.Klenow, "Development Accounting "[J], American Economic Journal: Macroeconomic, 2010(2).

[5] Hall Robert E, Charles I, "Why Do Some Countries Produce So Much More Output Per Worker Than Others?'[J]. The Quarterly Journal of Economics, 1999(1). 